\title{
To study the effect of epidural analgesia on second stage of labor and mode of delivery
}

\author{
Rakhee R. Sahu ${ }^{1, *}$, Shraddha M. Shivgan ${ }^{2}$ \\ ${ }^{1}$ Consultant, ${ }^{2}$ Senior Resident, Dept. of Obstetrics and Gynecology, Dr. L. H. Hiranandani Hospital. Mumbai, Maharashtra, India
}

*Corresponding Author: Rakhee R. Sahu

Email: rakhee.sahu@hiranandanihospital.org

Received: $6^{\text {th }}$ July, 2018

Accepted: $18^{\text {th }}$ August, 2018

\begin{abstract}
Epidural analgesia is regional anaesthesia that blocks pain in a particular region of the body. The use of epidural analgesia (EA) in labor is widespread in modern labor ward practice, and its benefits in terms of pain relief are well-recognized.

Aims: To study the effect of epidural analgesia on second stage of labor, maternal and neonatal outcomes and its efficacy in labor.

Study Design: This is Prospective Cohort Study was carried at Dr. L. H. Hiranandani Hospital. All the women admitted in labour room for delivery were divided into 2 groups.

1. Case Group: Included 84 women who opted for epidural analgesia.

2. Control Group: Included 90 women who did not take epidural analgesia.

Results: The $2^{\text {nd }}$ stage of labor in epidural group was $54.61( \pm 37.24)$ mins and $37.36( \pm 26.79)$ mins in the non epidural analgesia group. By using unpaired t-test, it was found that the data was significant $(\mathrm{p}=0.032)$.

The incidence of caesarean section in the epidural group was $16.66 \%$ and the in non-epidural group was $12.22 \%$. It was observed that epidural analgesia did not increase the rate of instrumental delivery or caesarean section.

The mean VAS Score before epidural analgesia was $6.2( \pm 1.07)$ whereas it was $3.95( \pm 1.46)$ after epidural analgesia. On applying Wilcoxon Matched Pair test, it was found that the pain was reduced significantly in the mothers after receiving the epidural analgesia.

Conclusion: Epidural analgesia can be safely recommended as a method of labor analgesia. Epidural analgesia has no significant adverse effects on maternal and neonatal outcomes
\end{abstract}

Keywords: Epidural analgesia, VAS - Visual analogue score, $2^{\text {nd }}$ stage of labour, Caesarean section.

\section{Introduction}

Epidural analgesia is regional anaesthesia that blocks pain in a particular region of the body. It blocks the nerve impulses from the lower spinal segments of the body. The goal is to provide pain relief during labor. According to the International Association for the study of pain, pain is an unpleasant sensory and emotional experience associated with actual potential tissue damage. Physiological pain is stimulated by noxious stimuli which activate nociceptive receptors.

Epidural analgesia is considered to be the most effective method of pain relief during labor and least depressant form of analgesia and is often the preferred choice of analgesia. ${ }^{1}$ Labor pains is one the most intense pains that a woman can experience. Epidural analgesia and combined spinal-epidural analgesia are the most widely used form of labor analgesia. ${ }^{2}$

\section{Aims and Objectives}

Aims: To study the effect of epidural analgesia on second stage of labor and its efficacy in labor.

\section{Objectives}

Primary Objective:

1. To evaluate the effect of epidural analgesia on the duration of second stage labor as compared to nonepidural analgesia group.

\section{Secondary Objectives}

1. To evaluate the effect of epidural analgesia on patient satisfaction for pain relief.

2. To evaluate the effect of epidural analgesia on mode of delivery.

3. To evaluate clinical outcomes of neonates in mothers receiving epidural analgesia (effect on APGAR score of neonates).

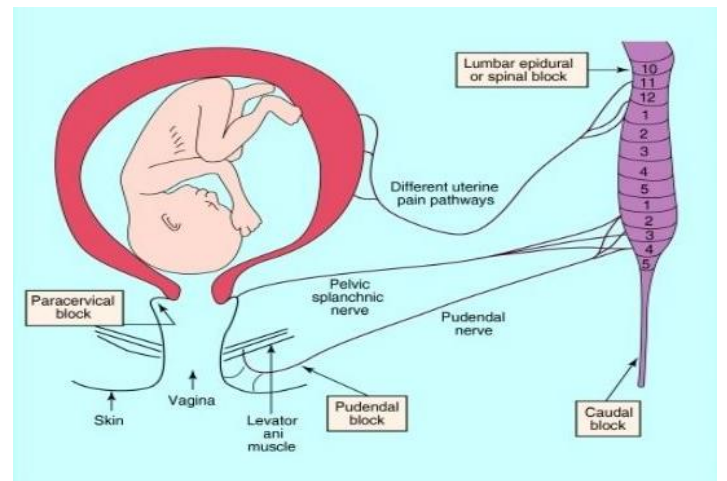

Fig. 1: Labor pain pathway 


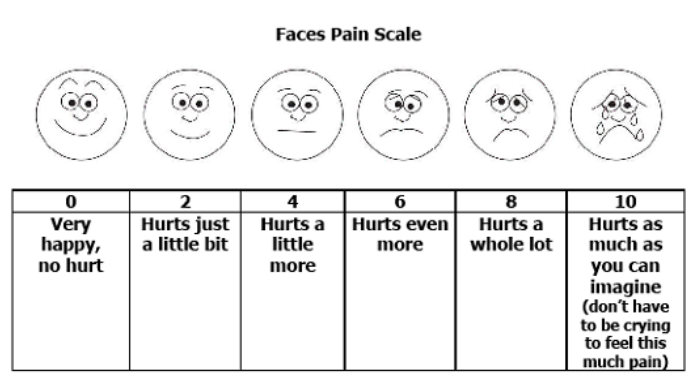

Fig. 2: Wong-baker faces pain rating scale

Visual Analog Scale (VAS)

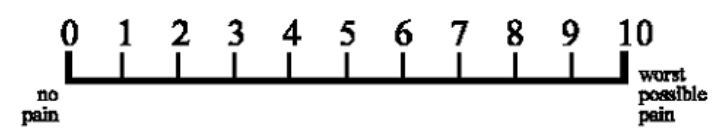

Fig. 3: Visual analogue pain scale

Procedure of Combined Spinal-Epidural Analgesia: Informed consent is obtained. The lumbar area where the epidural is to be given is prepped with an antiseptic solution. In the second or third lumbar space the skin is infiltrated with $2 \%$ lidocaine; a local anesthetic agent and then a median 16 or 18 gauge hollow Tuohy needle is introduced in the lower back at the level of vertebrae L3 or L4 and glided till it reaches the epidural space which is confirmed by loss of resistance to air. A pencil-point needle is introduced through the hollow needle into the subarachnoid space and the opioid drug is injected into the subarachnoid space through the needle and then the needle is removed after which a flexible catheter is placed in position and fixed in the epidural space.

The anaesthetic drugs used were either $0.1 \%$ Bupivacaine, $0.1 \%$ Ropivaciane or $0.1 \%$ Levobupivacaine along with Fentanyl. The volume of epidural was $10 \mathrm{ml}$ bolus (10 mg of Bupivacaine/ Ropivacaine/Levobupivacaine $+20 \mathrm{mcg}$ of Fentanyl) followed by continuous infusion at the rate of $6 \mathrm{ml} / \mathrm{hr}$. The continuous infusion dose was later titrated as per the patients requirement of pain relief. Top-up bolus dose was given in patients who complained of pain inspite of continuous infusion.

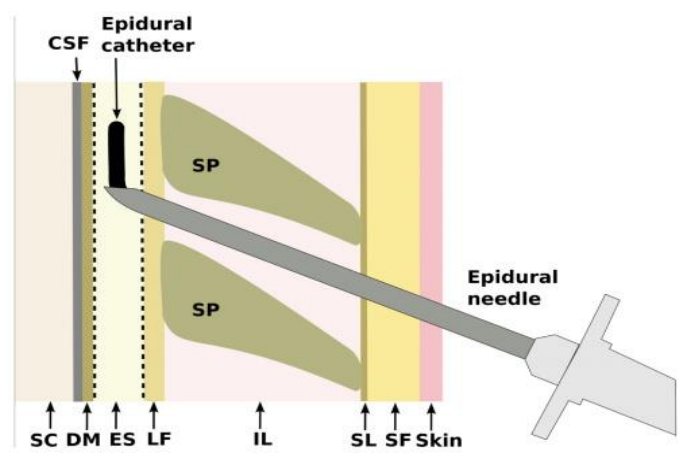

Fig. 4: Diagrammatic representation of procedure of epidural analgesia
After epidural analgesia, there may be transient alteration in fetal heart rate due to opioid induced uterine hyperstimulation and placental hypoperfusion. Placental hypoperfusion is due to fall in maternal blood pressure, unopposed norepinephrine secretion related to rapid onset analgesia and rapid fall in maternal epinephrine concentrations.

During epidural analgesia there is decrease in inhibitory effect of catecholamines on uterine contraction which is associated with shorter duration of first stage of labor.

The incidence and severity of pruritis is dependent on the opioid dose and is more frequent with intrathecal opioids than with epidural opioids. The exact mechanism of pruritis is unclear. ${ }^{5}$ Opioids interact with medullary inhibitory pathway in the spinal cord. Opioids may also act on itching centre in the medulla.

Epidural analgesia can be associated with post dural puncture headache (PDPH). PDPH is typically postural in nature and results from leakage of cerebrospinal fluid associated with decrease in intracranial pressure and compensatory cerebral vasodilatation. It can be treated with caffeine, sumatriptan, epidural blood patch.,

Epidural analgesia may cause urinary retention by interfering with parasympathetic outflow and causing detrusor muscle relaxation. ${ }^{6}$ Epidural analgesia may rarely cause life threatening complications like maternal convulsions, cardiovascular collapse after unintentional direct intravenous injection of a local anaesthetic agent; total spinal anaesthesia following unintentional intrathecal injection of local anaesthetic agent; spinal and epidural hematomas. ${ }^{4}$ Very rarely it may cause epidural abscess or meningitis.

\section{Review of Literature}

Agarwal et al (2011-2014) conducted a study on the effect of epidural analgesia on labor, mode of delivery and neonatal outcome in nulliparous women in India comprising of 120 nulliparous parturient women. The duration of first stage of labor was shorter in epidural group (4 hours) as compared to control group (5.48 \pm 1.56 hours). The duration of second stage was longer in the epidural group (33.13 \pm 12.78 mins) as compared to the control group (27.53 \pm 11.73 mins). There was no significant rise in the caesarean delivery or instrumental assisted vaginal delivery in the epidural group. ${ }^{9}$

Another retrospective cohort study published in 2011 to identify the relation between epidural analgesia (EA) and instrumental assisted delivery (IAD) rate showed that there was no significant association between the use of epidural analgesia and increased instrumental assisted delivery rate. ${ }^{10}$

A retrospective cohort study (2013) in 7,260 nulliparous and 6,677 multiparous parturient were administered epidural analgesia. Epidural analgesia was a significant risk in both nulliparous and multiparous 
parturient for operative vaginal delivery than for caesarean section. ${ }^{11}$

Mousa WF, et al (2012) included 160 nulliparous parturient women and allocated them in the epidural group and the control group and found that there was no significant difference in the duration of first $(\mathrm{P}=0.35)$ and second stage of labor $(\mathrm{P}=0.41)$ in both groups. ${ }^{12-14}$

A Retrospective observational cohort study published in December 2014, included 5593 parturient women singleton pregnancy, cephalic presentation, more than 37 weeks of gestation. Epidural analgesia is an important risk factor for low cord arterial $\mathrm{pH}<7.10$ (Odds ratio $=1.98,95 \%$ CI 1.28-3.09, $\mathrm{p}=0.0023$ ) and associated with low APGAR score at 7 minute (Odds ratio $=4.55,95 \%$ CI $2.35-8.80, \mathrm{p}<0.0001)$. There was no significant difference in APGAR score at 5 minute. ${ }^{15}$

Bannister-Tyrrell M, et al (2010) described a cohort study on epidural analgesia in labor and risk of caesarean delivery. Epidural analgesia in labor was associated with increased risk of caesarean delivery \{risk ratio $[R R] 2.5,[95 \%$ confidence interval (CI) 2.5, 2.6] $\}.{ }^{16}$

Wassen MM (2010), et al conducted a retrospective cohort study including $13,78,458$ women, singleton, cephalic term gestation (2000- 2009) and was observed that epidural analgesia did not increase the rate of caesarean section and instrumental vaginal delivery in nulliparous women $(+2.8 \%$ and $-3.3 \%$, respectively) whereas among multiparous women the rate of caesarean section changed slightly $(+0.8 \%$ and $0.7 \%$, respectively). ${ }^{17}$

\section{Materials and Methods}

Type of Study: This is a hospital based prospective cohort study

Study Site: This study was carried out by collecting data from the patients admitted to the Labor Room for delivery at Dr. L.H. Hiranandani Hospital Powai, Mumbai after obtaining clearance from the hospital ethics and scientific committee.

\section{Study Design:}

1. Case Group: included 84 women who opted for epidural analgesia.

2. Control Group: included 90 women who did not take epidural analgesia.

Study Duration: 15 June -2016 to 14 June -2017.

\section{Inclusion Criteria}

1. 18-35 years of age

2. Single fetus, vertex presentation, term gestation.

3. Cervical dilatation $4 \mathrm{~cm}$ or more.

4. Admission test reactive.

5. American Association of Anaesthesiologists physical status 1 and 26 . Request for analgesia

\section{Exclusion Criteria}

1. American Society of Anaesthesiologists status more than 2 (Uncontrolled medical comorbidities).

2. Platelet count less than $80000 /$ cu.mm.

3. History suggestive of blood dyscrasia or bleeding disorder.

4. Low molecular weight heparin given within last 12 hours if on prophylactic dose (20mg or $40 \mathrm{mg}$ ) or last 24 hours if on therapeutic dose (more than 40 $\mathrm{mg}$ ).

5. Local skin infection at the site of epidural.

6. Allergy to local anaesthetic agents.

\section{Methodology:}

Data collection methods: All data was entered in a master-chart using Microsoft Excel 2013.

Statistical Methods: This is a prospective cohort study. We calculated the means and Standard deviation for continuous variables, and proportions for the categorical variation. The means between groups were compared using the 't test' and Analysis of Variance (ANOVA) for more than two groups. The proportions were compared using the Chi Square test or Fishers exact test for low expected cell counts. A P value of $<0.05$ was considered statistically significant in our analysis.

\section{Results}

Table 1: Demographic data

\begin{tabular}{|l|c|c|c|}
\hline Variable & Epidural analgesia Group: $\mathbf{n = 8 4}$ & $\begin{array}{c}\text { Non Epidural Analgesia } \\
\text { Group: } \\
\mathbf{n = 9 0}\end{array}$ & $\begin{array}{c}\text { P Value } \\
(<\mathbf{0 . 0 5}-\text { significant })\end{array}$ \\
\hline Age & $30.17 \pm 2.5$ & $30.15 \pm 4.1$ & 0.5441 \\
\hline Height & $158 \pm 7.5$ & $157.9 \pm 6.9$ & 0.9184 \\
\hline Weight & $74.25 \pm 10.57$ & $72.52 \pm 12.07$ & 0.3226 \\
\hline BMI & $29.55 \pm 4.3$ & $28.55 \pm 4.6$ & 0.0509 \\
\hline
\end{tabular}

$\mathrm{p}$ Value $<0.05$ was considered to be significant for all variables. Values are described as Mean \pm SD. Unpaired t-test has been applied to all the above variables. Since $\mathrm{p}$ Value $>0.05$ in case of age, height, weight and BMI of epidural analgesia group compared to non epidural analgesia group, the above data is comparable to each other and not considered to be statistically significant. 
All patients belonging to the epidural analgesia group were compared to the patients

in the Non-epidural analgesia group for demographic characteristics.

Table 2: Comparison of duration of active phase of $1^{\text {st }}$ stage of labor in epidural analgesia group v/s non epidural analgesia group

\begin{tabular}{|l|c|c|c|}
\hline Groups & $\begin{array}{c}\text { Epidural: } \\
\mathrm{n}=84\end{array}$ & $\begin{array}{c}\text { Non-Epidural: } \\
\mathrm{n}=90\end{array}$ & $\begin{array}{c}\mathrm{p} \text {-Value: } \\
(<0.05-\text { significant })\end{array}$ \\
\hline Time Taken & $4.28( \pm 1.5) \mathrm{hrs}$ & $5.6( \pm 1.4) \mathrm{hrs}$ & 0.0007 \\
\hline
\end{tabular}

Since $\mathrm{p}$ Value $<0.05$ in case of duration active Phase of $1^{\text {st }}$ Stage of labor of epidural analgesia group compared to Non epidural analgesia group, the above data is considered to be statistically significant.

Table 3: Comparison of duration of $2^{\text {nd }}$ stage of labor in epidural analgesia group v/s non epidural analgesia group

\begin{tabular}{|l|c|c|c|}
\hline Groups & $\begin{array}{c}\text { Epidural: } \\
\mathrm{n}=84\end{array}$ & $\begin{array}{c}\text { Non-Epidural: } \\
\mathrm{n}=90\end{array}$ & $\begin{array}{c}\mathrm{p} \text {-Value: } \\
(<0.05-\text { significant })\end{array}$ \\
\hline Time Taken & $54.61( \pm 37.24) \mathrm{mins}$ & $37.36( \pm 26.75) \mathrm{mins}$ & 0.032 \\
\hline
\end{tabular}

Since $\mathrm{p}$ Value $<0.05$ in case of duration of $2^{\text {nd }}$ Stage of labor of epidural analgesia group compared to Non epidural analgesia group, the above data is considered to be statistically significant

Table 4: Comparison of mode of delivery in epidural analgesia group v/s non epidural analgesia group

\begin{tabular}{|l|c|c|c|}
\hline \multicolumn{1}{|c|}{ Groups } & $\begin{array}{c}\text { Epidural analgesia } \\
\text { No. of patients (\%) }\end{array}$ & $\begin{array}{c}\text { Non Epidural analgesia } \\
\text { No. of patients (\%) }\end{array}$ & $\begin{array}{c}\text { P Value } \\
\text { Using chi-square test }\end{array}$ \\
\hline FTND & $40(47.61 \%)$ & $51(56.66 \%)$ & 0.0460 \\
\hline Vacuum & $30(35.71 \%)$ & $28(31.11 \%)$ & 1.0 - not significant \\
\hline LSCS & $14(16.66 \%)$ & $11(12.22 \%)$ & 0.8056 - not significant \\
\hline Total (no. of patients) & 84 & 90 & 174 \\
\hline
\end{tabular}

It was observed that epidural analgesia did not increase the rate of instrumental assisted vaginal delivery or caesarean section.

Table 5: Comparison of indication of LSCS in epidural analgesia group vs non epidural analgesia group

\begin{tabular}{|l|c|c|c|c|c|c|}
\hline $\begin{array}{c}\text { Indication for } \\
\text { LSCS }\end{array}$ & $\begin{array}{c}\text { Foetal Distress } \\
(\mathbf{n} / \%)\end{array}$ & $\begin{array}{c}\text { NPOL } \\
(\mathbf{n} / \%)\end{array}$ & $\begin{array}{c}\text { MSAF } \\
(\mathbf{n} / \%)\end{array}$ & $\begin{array}{c}\text { Others } \\
(\mathbf{n} / \%)\end{array}$ & Total & p-value \\
\hline Epidural & $3(21.42)$ & $5(33.33)$ & $2(14.28)$ & $4(28.57)$ & 14 & \\
\hline Nonepidural & $4(36.36)$ & $2(18.18)$ & $2(18.18)$ & $3(27.27)$ & 11 & 0.8056 \\
\hline
\end{tabular}

There was no significant difference in the rate of LSCS across two groups. Non Progress of labor was the most common indication in epidural analgesia group and Foetal distress was the most common indication in the non epidural analgesia group. The other reason for LSCS being foetal malpresentation like persistent occipito posterior, deflexed head, early abruption, Nuchal cord and patient not willing for trial of labor.

All the patients underwent visual analog pain scoring pre and post epidural analgesia. Out of 84 patients in the study group, 61 women (72.61\%) complained of pain score between 6-8 which corresponds to immense pain and 23 women complained of moderate pain which corresponds to score between 4-6. After epidural analgesia 67 women experienced significant pain relief with VAS pain Score between (2-4), 5 women had moderate pain relief with VAS score between 4-6. But 10 women said there was no appreciable decrease in pain after epidural analgesia. Top- up epidural analgesia of $5 \mathrm{ml}$ bolus was given in total 22 women.

Table 6: Pain scores before and after epidural analgesia in the study group $(b)$

\begin{tabular}{|l|c|c|c|}
\hline Groups & Pre-Epidural & Post-Epidural & p-Value \\
\hline Mean & $6.2( \pm 1.07)$ & $3.95( \pm 1.46)$ & \multirow{2}{*}{0.0058} \\
\hline Median (Range) & $7(5-8)$ & $3.5(1-8)$ & \multirow{2}{*}{} \\
\hline
\end{tabular}

$\mathrm{p}$ Value $<0.05$ was considered to be significant for all variables. Wilcoxon Matched Pair Test has been applied to all the above variables. Since $\mathrm{p}$ Value $=0.0058$ in the pre-epidural analgesia group compared to the post-epidural analgesia group, the above data is considered to be statistically significant.

In the epidural analgesia group, after adequate analgesic infusion titration the VAS Scale score improved from $6.2( \pm 1.07)$ to $3.95( \pm 1.46)$. On applying Wilcoxon Matched Pair test, it was found that 
the pain was reduced significantly in the mothers after receiving the epidural analgesia.

The APGAR score of $9 / 10$ was noted in $65(77.38 \%)$ neonates in the epidural group and 70 $(77.77 \%)$ neonates in the non- epidural group. There was no significant difference in the APGAR score of neonate in both the groups. There was no neonatal morbidity noticed in our study in both the groups.

Table 7: To Study the adverse effects of epidural analgesia

\begin{tabular}{|l|c|}
\hline \multicolumn{1}{|c|}{ Adverse effects } & $\begin{array}{c}\text { Epidural } \\
\text { Analgesia }\end{array}$ \\
\hline Itching & $55(65.47 \%)$ \\
\hline Lower limb paresis & $2(2.38 \%)$ \\
\hline $\begin{array}{l}\text { Post epidural analgesia } \\
\text { Hypotension }\end{array}$ & $12(14.28 \%)$ \\
\hline Post epidural bradycardia & $5(1.19 \%)$ \\
\hline Post delivery Urinary retention & $1(1.19 \%)$ \\
\hline
\end{tabular}

\section{Discussion}

The use of epidural analgesia (EA) in labor is widespread in modern labor ward practice, and its benefits in terms of pain relief are well-recognized.

Majority of the obstetricians had the perception of EA prolonged the first stage $(89.5 \%)$ and second stage (98.2\%) of labor, increased the rate of caesarean section $(87.7 \%)$, instrumental delivery $(58.8 \%)$ and increased the incidence of backache $(85.5 \%)$. None of the obstetricians received any formal training in EA. Majority of the Obstetricians (84.2\%) were not sure if they would recommend EA to their patients. These findings are therefore very reflective of the lack of knowledge, application \& practice regarding the topic and hence also prompted us to perform a prospective study to observe for various such findings in a systematic manner. ${ }^{18}$

In our study, the duration of Active Phase of $1^{\text {st }}$ Stage of labour was analysed. The mean duration of active phase was $4.28( \pm 1.5) \mathrm{hrs}$ in the epidural analgesia group whereas it was $5.6( \pm 1.4) \mathrm{hrs}$ in the non-epidural analgesia group and the duration was significantly less the epidural analgesia group when compared to the non-epidural analgesia group. Similar study conducted by Agarwal et al (2011-2014) ${ }^{9}$ showed that the duration of active phase of labour was considerably shorter in the epidural analgesia group when compared to the non-epidural group; which is similar to our findings.

In our study, the $2^{\text {nd }}$ stage of labor in epidural analgesia group was $54.61( \pm 37.24)$ mins and in the non-epidural analgesia group was $37.36( \pm 26.79)$ mins respectively and using unpaired $\mathrm{t}$-test, it was found that the data was significant $(\mathrm{p}=0.032)$. In the study conducted by Agarwal et al (2011-2014), ${ }^{9}$ the duration of second stage was longer in the epidural analgesiagroup $(33.13 \pm 12.78)$ as compared to control group (27.53 \pm 11.73$)$.There was a significant difference in both the groups. In a retrospective cohort study published in $2011,{ }^{10}$ the duration of second stage of labor was 60 minutes in the epidural analgesia group and 40 minutes among the control group $(\mathrm{p}<0.0005)$. Mousa WF, et al (2012) $)^{12}$ found that there was no significant difference in the second stage of labor $(\mathrm{P}=0.41)$ in both groups

In our study, the mode of delivery of mothers in both the epidural analgesia group as well as Non epidural analgesia group showed a similar incidence of vacuum deliveries and caesarean section. Agarwal et al (2011-2014) ${ }^{9}$ conducted study which showed no significant rise in the caesarean delivery or instrumental assisted vaginal delivery in the epidural analgesia group. However a retrospective cohort study was published in $2013^{11}$ showed that epidural analgesia was a significant risk in both nulliparous and multiparous parturients for operative vaginal delivery than for caesarean section.

Wassen MM (2010) ${ }^{17}$ conducted a study which showed that epidural analgesia did not increase the rate of caesarean section and instrumental vaginal delivery in nulliparous women $(+2.8 \%$ and $-3.3 \%$, respectively) whereas among multiparous women the rate of caesarean section changed slightly $(+0.8 \%$ and $0.7 \%$, respectively).

The mean VAS pain Score before epidural analgesia was $6.2( \pm 1.07)$ whereas it was $3.95( \pm 1.46)$ after epidural analgesia, it was found that the pain was reduced significantly in the women after receiving the epidural analgesia. In a similar study conducted by Maj Indranil Sikdar in $2013,{ }^{20}$ it was studied that mean visual analog scale score before epidural analgesia was 8.34 whereas it was 2.20 after epidural analgesia. There was significant difference between pre and post epidural VAS score.

In our study, there was no statistical difference in the APGAR score of the neonate in both group, which was similar to studies conducted by Agarwal et al (2011-2014) ${ }^{9}$ except a retrospective cohort study which was published in $2013^{11}$ showed that 1 minute APGAR score was less than 7 in the nulliparous women (1.3\%) who were administered epidural analgesia as compared to $0.7 \%$ who were not administered epidural analgesia.

\section{Conclusion}

In our study, the duration of active Phase of $1^{\text {st }}$ stage of labour was $4.28( \pm 1.5) \mathrm{hrs}$ in the epidural analgesia group whereas it was $5.6( \pm 1.4) \mathrm{hrs}$ in the non-epidural analgesia group and the duration was significantly less the epidural analgesia group when compared to the non-epidural analgesia group. The $2^{\text {nd }}$ stage of labor in epidural group was $54.61( \pm 37.24)$ mins and $37.36( \pm 26.79)$ mins in the non epidural analgesia group. The $2^{\text {nd }}$ stage of labor was prolonged in women who opted for epidural analgesia. The results showed that there was no significant difference in 
the incidence of instrumental assisted vaginal delivery or caesarean section in both the groups.

It was observed that epidural analgesia did not increase the incidence of caesarean section. In the epidural group, $79.76 \%$ of women were satisfied with pain relief due to epidural analgesia. In our study, there no statistical difference in APGAR score of neonates in both the groups. In the epidural analgesia group, minor side effects like itching, hypotension, lower limb paresis and urinary retention were noted.

\section{Recommendations}

1. Epidural analgesia can be safely recommended as a method of labor analgesia.

2. Although epidural analgesia may increase the duration of second stage of labour but does not significantly increase the incidence of instrumental delivery or caesarean section.

3. Epidural analgesia has no significant adverse effects on maternal and neonatal outcomes.

\section{Conflict of Interest: None.}

\section{References}

1. Hawkins JL. Epidural analgesia for Labor and delivery. $N$ Engl J Med. 2010;362:1503-10.

2. Simmons SW, Taghizadeh $\mathrm{N}$ et al. Combined spinalpidural versus epidural analgesia in labor (Review) The Cochrane collaboration 2012;12.

3. Ronald D. Miller. Anesthesia for Obstetrics Millers Anesthesia $6^{\text {th }}$ edition Chapter 58 Page no 2327-2329)

4. Neuraxial opioid-induced pruritus: J Anaesthesiol Clin Pharmacol. 2013;29(3):303-307. doi: 10.4103/09709185.117045

5. John L Atlee Complication of anaesthesia. 2007 Page no 262.

6. Rachael E Collis Obstetrics anaesthesia 2002 Chapter 6 Regional Analgesia for Labor Page no 95.

7. Sprigge JS, Harper SJ "Accidental dural puncture and post dural puncture headache in obstetric anaesthesia: presentation and management: a 23-year survey in a district general hospital". Anaesthesia. 2008;63(1):36-43. doi:10.1111/j.1365-2044.2007.05285.x. PMID 18086069

8. Doughty A. Walter Stoeckel (1871-1961): A pioneer of regional analgesia in obstetrics. Anaesthesia. 1990;45:468-471.

9. Dipti Agrawal, Bela Makhija. The Effect of Epidural Analgesia on Labor, Mode of Delivery and Neonatal Outcome in Nullipara of India, 2011-2014.

10. Rimaitis K, Klimenko O. Retrospective case-control study: Labor epidural analgesia and the incidence of instrumental assisted delivery. Medicina (Kaunas). 2015;51(2):76-80. doi: 10.1016/j.medici.2015.02.002.

11. Ti-Ho Hung, Tsang-Tang Hsieh. Retrospective cohort study Differential Effects of Epidural Analgesia on Modes of Delivery and Perinatal Outcomes between Nulliparous and Multiparous Women March 2015.

12. Wesam Farid Mousa, Roshdi Al-Metwalli. Epidural analgesia during labor vs no analgesia: A comparative study. J Anaesth. 2012;6(1):36-40. doi: 10.4103/1658354X.93055PMCID: PMC3299112
13. Anim-Somuah M, Smyth R, Howell C. Epidural versus non-epidural or no analgesia in labor. Cochrane Database Syst Rev. 2005;4:CD00331.

14. Impey L, MacQuillan K, Robson M. Epidural analgesia need not increase operative delivery rates. Am J Obstet Gynecol. 2000;182:358-63.

15. Hincz P, Podciechowskil L. Epidural analgesia during labor: a retrospective cohort study on its effects on labor, delivery and neonatal outcome. Ginekol Pol. 2014;85(12):923-8.

16. Bannister-Tyrrell M, Ford JB, Morris JM, Roberts CL. Epidural analgesia in labor and risk of caesarean delivery. (Paediatr Perinat Epidemiol. 2014;28(5):40011. doi: 10.1111/ppe.12139. Epub 2014 Jul 18.

17. Wassen MM, Hukkelhoven CW. Epidural analgesia and operative delivery: a ten-year population-based cohort study in The Netherlands. Eur J Obstet Gynecol Reprod Biol. 2014;183:125-31.

doi:

10.1016/j.ejogrb.2014.10.023. Epub 2014 Oct 30.

18. Sohaib M, Ismail S. Does labor epidural slow the progress of labor and lead to complications? Obstetricians' perception working in private and public sector teaching hospitals in a developing country. Indian Journal of Anaesthesia. 2015;59(12):779-784. doi:10.4103/0019-5049.17

19. Sharma SK, McIntire DD, Wiley J, Leveno KJ. Labor analgesia and cesarean delivery: an individual patient meta-analysis of nulliparous women. Anesthesiology. 2004;100:142-48.

20. Maj Indranil Sikdar, Col Shivinder Sinbh. A prospective review of the labor analgesia programme in a teaching hospital. Medical Journal Armed Forces India. 2013;69:361-365.

21. Henry A, Nand SL. Intrapartum pain management at the Royal Hospital for Women. Aust N Z J Obstet Gynaecol. 2004;44(4):307-13.

22. Anim Somuah M, Smyth RM, Jones L. Epidural versus nonepidural or no analgesia in labor. Cochrane Database Syst Rev. 2011;12(12):CD000331. doi: 10.1002/14651858.CD000331.pub3.

How to cite this article: Sahu R. R, Shivgan S. M. To study the effect of epidural analgesia on second stage of labor and mode of delivery. Indian $\mathrm{J}$ Obstet Gynecol Res. 2018;5(4):553-558. 